\title{
Disparities in exposure to tobacco smoke pollution at Romanian worksites
}

\author{
Dorota Kaleta', Adam Fronczak' \\ 1 Tobacco Control Department, Department of Preventive Medicine, Medical University of Łódź, Poland
}

Kaleta D, Fronczak A. Disparities in exposure to tobacco smoke pollution at Romanian worksites. Ann Agric Environ Med. $2015 ; 22(4): 755-761$. doi: $10.5604 / 12321966.1185789$

\begin{abstract}
Introduction. Differences in the risk of being exposed to second-hand smoke (SHS) in the workplace may occur not only between countries, but also within a country among socio-economic groups.

Objectives. The aim of the study was to examine the associations of exposure to SHS at worksites with selected factors in non-smoking Romanian employees.

Material and Methods. Data on exposure to SHS at worksites and other characteristics of respondents came from the Global Adult Tobacco Survey (GATS). GATS is a nationally representative household survey of adults 15 years of age or older, using a standard protocol.

Results. Among 4,517 respondents who completed the questionnaire there were 1,333 subjects, including 859 non-smokers who worked in an indoor area outside the home. The prevalence of exposure to SHS was 31.2\% among non-smoking male and $23.9 \%$ among non-smoking female employees $(p<0.05)$. Employees with primary education had odds of exposure to SHS at work nearly twice as high, compared to the respondents having high education attainment $(\mathrm{OR}=1.9 ; 95 \% \mathrm{Cl}$ : 1.2-2.9). Moreover, exposure to SHS at worksites was significantly associated with a low level of support for tobacco control policies among workers (OR $=1.8 ; 95 \% \mathrm{Cl}: 1.2-2.8)$.

Conclusions. In spite of the increasing presence of smoking bans in public and workplaces, enforcement still seems to be unsuccessful in the occupational space in Romania. In order to reduce SHS exposure in workplaces, strengthening support for tobacco control policies is essential.
\end{abstract}

\section{Key words}

second-hand smoke, workplace, employee, adults, GATS, Romania

\section{INTRODUCTION}

Second-hand smoke is formed from the side-stream smoke emitted into the environment from smouldering cigarettes and other tobacco products between puffs, and from the mainstream smoke exhaled by the smoker [1]. The strongest evidence exists in adults for lung cancer, ischaemic heart disease, and asthma (new cases), and in children for low birth weight, and sudden infant death syndrome (SIDS), childhood chronic respiratory symptoms, lower respiratory illness in young children, asthma (new cases and exacerbation), middle-ear effusion and infection in young children, and pulmonary function among children [2]. Lung cancer among non-smokers is causally related to SHS, both from spousal exposure and from exposure at work; the suggested ORs are $1.21(1.13-1.30)$ and $1.22(1.13-1.33)$, respectively [3]. Of the burden in non-smokers, SHS is estimated to cause about 21,000 deaths and about 216,000 DALYs due to lung cancer worldwide. A recent review concluded that SHS exposure is associated with increased risk for IHD mortality, morbidity, and symptoms. The overall pooled estimate related to any SHS exposure among non-smokers was 1.27 (1.19-1.36). The effects of home and workplace exposures are expected to be additive. The total DALYs from IHD attributable to SHS exposure worldwide is estimated to reach 2.8 million. The strongest evidence for SHS exposure and onset of adult asthma comes from the Finnish Environment and Asthma Study, which was a population-based incident case-control

Address for correspondence: Dorota Kaleta, Department of Preventive Medicine, Medical University, Zeligowskiego 7/9, 90-752 Lodz, Poland.

e-mail:dkaleta@op.pl

Received: 22 June 2015; accepted: 14 September 2015 study that corresponded to a follow-up of approximately 100,000 adults for 5.8 years, in a geographically-defined area in southern Finland. It was based the diagnosis of asthma on extensive clinical and lung function investigations, which ascertained detailed SHS exposure history both at home and at work in the past 12 months and over a lifetime, adjusted for a large set of potential confounders. Based on the Finnish study, the relative risk estimate suggested for the disease burden calculation is 1.97 (95\% CI 1.19-3.25) for SHS exposure at work and/or at home [4].

It should be stressed that SHS-related deaths also occur among individuals who have decided not to smoke and whose increased risk of disease and death is therefore involuntary [3]. This has a considerable human aspect for individual workers and their families who may be non-smokers, as well as having a broader economic impact. Exposure to SHS imposes significant costs on the economy, including direct costs stemming from increased healthcare expenditure and indirect costs linked to productivity losses.

In Romania, tobacco smoke is estimated to be responsible for $16 \%$ of all NCDs, compared with $20 \%$ of all communicable diseases [5]. Within the communicable diseases group, deaths attributed to tobacco accounted for $21 \%$ of all lower respiratory infection deaths and $27 \%$ of all tuberculosis deaths. The death rate due to tobacco in males was 510 per 100,000 (males aged 30 years and over), compared with females - 104 per 100,000 (females aged 30 years and over). The proportion of deaths attributable to tobacco was approximately $24 \%$ for males and $6 \%$ for females. Among those who died prematurely, almost one in every 4 deaths (population aged 30-44) and one in 3 deaths (population aged 45-59 years) were attributable to tobacco use. Among the age group 45-59 years, tobacco use 
accounted for $36.6 \%$ of deaths due to a lower respiratory infection, $54.2 \%$ of deaths due to all cardiovascular diseases, and $88.4 \%$ of those who had died from cancer of the trachea, bronchi and lungs. The estimates indicate that the deaths and DALYs attributable to SHS represent approximately $12 \%$ of deaths, and $19 \%$ of disability-adjusted life years (DALYs) attributable to active smoking [1].

Eastern European countries lag behind the West in implementing smoking bans in public places and workplaces, which has resulted in huge differences in the prevalence of SHS exposure between EU Member States. But differences in the risk of being exposed to SHS may also occur withincountry, between socio-economic groups. In all countries, the evidence related to SHS exposure needs to be constantly accumulated in order to implement well-targeted programmes and policies for the effective protection of workers and improvement safety at work. Therefore, the purpose of this study was to examine the associations of exposure to secondhand smoke (SHS) at worksite with selected factors in nonsmoking Romanians.

\section{MATERIALS AND METHOD}

Data on exposure to SHS at worksites, smoking status, and other characteristics of respondents came from the Global Adult Tobacco Survey (GATS), the global standard to systematically monitor adult tobacco use and track key tobacco control indicators. GATS is a nationally representative household survey of adults 15 years of age or older, using a standard protocol. It is intended to generate comparable data within and across countries. GATS enhances countries' capacity to design, implement and evaluate tobacco control interventions. The methodology of the survey has been described in detail elsewhere $[6,7,8]$.

In 2011, Romania implemented GATS, a cross-sectional, nationally representative household survey [9], target population: non-institutional residents of Romania. According to the GATS sample selection requirements, a multi-phase sampling for GATS Romania was conducted in which a subsample of primary sampling units (PSUs) was selected from the Master Sample EMZOT (Multifunctional Sample on Territorial Areas) [6]. The final probability selection of the sample units was equivalent to that of being selected under three- stage stratified-cluster sampling in order to produce key indicators for the country as a whole, as well as by residence (urban or rural) and by gender. Of the 5,629 sampled households, 4,601 completely filled in the household interview, and the computed household response rate was $89.9 \%$. The household response rate was higher in rural areas than in urban areas (95.8\% and $85.6 \%$, respectively). Among individuals selected from the completely screened households, 4,517 completed the individual interview, and the person-level response rate was $98.4 \%$. The total response rate was $88.5 \%$. GATS data were collected electronically by pollsters during face-to-face interviews.

Study variables. The outcome variable was exposure to SHS at worksites among non-smoking adults working in an indoor area outside the home in Romania. Exposure to second-hand smoke in indoor places at work was assessed in the 30 days prior to the interview, based on the question: 'During the last 30 days, did anyone smoke in the indoor areas in which you work?' among those respondents who work outside of the home who usually work indoors. Respondents who indicated 'yes' were classified as exposed to SHS in the workplace. Adults who work indoors and were exposed to tobacco smoke at work were further differentiated by smoking status, selected demographic characteristics, awareness of secondhand smoke and smoking harmfulness, among other factors.

For the purpose of the current analysis, only data from non-smokers (never smokers and former smokers) were used. Former smokers were considered those respondents who have ever smoked in their life, but did not smoke at the time of the survey. Furthermore, the worksite smoking policies in indoor areas were assessed and subsequent categories were established:

- smoking allowed everywhere;

- smoking allowed in some indoor areas;

- smoking prohibited in all indoor areas;

- no policy.

Awareness of the health consequences of smoking was assessed by asking the question: 'Do you think that tobacco smoking causes serious diseases?' Respondents were classified as being aware if they answered 'yes', and as unaware if they answered 'no' or 'do not know'. Awareness of the health consequences of SHS exposure were similarly assessed. Finally, support for tobacco control policies among respondents was evaluated by differentiating between high, medium and low level support. This measure was based on eight questions specifying different items of tobacco control policies. The sum score was divided as supporting 4-5 policies (high level support), 2-3 policies (medium level) and $0-1$ policy (low level).

Socio-demographic variables. Age was analyzed in the following groups: $15-29,30-39,40-49, \geq 50$ years old. For educational level, respondents were classified as having completed primary education, secondary education, or higher education. Economic activity differentiated subjects who were currently employed, unemployed, and economically non-active (i.e. pupils, students, homemakers, retirees, and pensioners due to disability). Among the economically active respondents, government employee and non-government together with self-employed respondents were considered. Socio-economic circumstances, including ownership of different household items, were also evaluated. The variable called 'asset index' was created based on the summative score of possession of the following assets: functioning electricity, flush toilet, fixed telephone, cell telephone, television, radio, refrigerator, car, washing machine, computer, internet access. The summative score was then divided into high, medium and low.

Statistics. STATISTICA Windows XP version 8.0 programme was used to perform the statistical analysis. First, a descriptive analysis for all variables included in the study was completed. Logistic regression analyses of unweighted data was then we used to calculate odds ratios (ORs) and 95\% confidence interval (CI) of each indicator on the outcome measure. In the first stage, crude coefficients - odds ratios (OR) of the impact of odd variables on the exposure to SHS in the workplace among males and females were calculated. In the next step, multi-factorial analysis of the simultaneous effect of all statistically significant variables on the probability of SHS exposure was studied. 


\section{RESULTS}

Among the 4,517 respondents who completed the questionnaire there were 1,333 subjects ( 757 males and 576 females) who worked in an indoor area outside the home. Out of 757 male employees there were $37.0 \%(n=280)$ of subjects exposed to SHS at worksites (including 145 smokers and 135 non-smokers), and 447 non-exposed (149 smokers and 298 non-smokers). Among 576 female employees, 28.5\% ( $n=164)$ declared being exposed to SHS at work (including 62 smokers and 102 non-smokers), and 412 non-exposed (including 88 smokers and 324 non-smokers). The prevalence of exposure to SHS was $31.2 \%$ among non-smoking males and $23.9 \%$ among non-smoking female employees $(\mathrm{p}<0.01)$. Characteristics of male and female non-smoking respondents exposed and non-exposed to second-hand tobacco smoke at worksites by selected socio-economic characteristics are presented in Tables 1 and 2. Statistically significant differences in the prevalence of exposure to SHS were observed for several of the tested characteristics, including education and support for tobacco control policies in males, and job classification in both genders. Moreover, among respondents employed in workplaces where smoking was prohibited in all indoor areas, $20.7 \%$ of male and $20.6 \%$ of females were exposed to ETS.

The results of the regression analyses among non-smokers are presented in Table 3. Univariable analyses showed that males had statistically significantly higher odds of being exposed to SHS, compared to females (Tab. 3). An association was found between education and support for tobacco control policies with ETS exposure. No statistically significant associations were found for age, place of residence, awareness of smoking, SHS health consequences, or asset index.

In multivariable analyses, the effect of gender was statistically insignificant. Non-smoking employees with primary education had odds nearly twice high for SHS exposure at work, compared to respondents having a higher education ( $\mathrm{OR}=1.9 ; 95 \% \mathrm{CI}: 1.2-2.9)$. Increased odds for SHS risk at worksite were also associated with a low level of support for tobacco control policies declared by respondents. Declaring a low level of support for tobacco control policies was significantly associated with higher odds of being exposed to SHS at a worksite (OR $=1.8 ; 95 \% \mathrm{CI}$ : $1.2-2.8)$. Other factors were not associated with exposure to SHS in the workplace.

\section{DISCUSSION}

GATS Romania revealed that $27.6 \%$ of non-smoking employees were exposed to SHS in the workplace. This figure is comparable with prevalence of work SHS in post-Soviet countries with $33.6 \%$ in Poland, 26.8\% in Russia, and 26.0\% in Ukraine [10]. However, compared to global statistics, Romania is placed in the middle of GATS countries, with SHS exposure at work reaching 54.6\% in Bangladesh, $21.7 \%$ in Brazil, 54.9\% in China, 57.3\% in Egypt, 26.1\% in India, 16.4\% in Mexico, 28.0\% in the Philippines, $23.6 \%$ in Thailand, $31.1 \%$ in Turkey, and $15.6 \%$ in Uruguay [10]. On the other hand, the Eurobarometer 2012 results showed that in Romania only $38 \%$ of employees were never or almost never exposed to tobacco smoke indoors at their, compared to $72 \%$ for the 27 of EU countries. The presented study in Romania reported the highest occurrence of SHS at worksite among EUs countries
[11], but it was not possible to directly compare results of the GATS and the Eurobarometer due to different methodology used in those studies.

Even though Romanian law bans smoking in health care facilities (total) and in all governmental buildings, schools, and universities (smoking permitted only in special designated rooms), $16 \%$ of male and $34 \%$ of female government employees declared being exposed to SHS [6]. Another important finding is that over $20 \%$ of nonsmoking respondents were exposed to SHS in the workplaces in Romania, regardless of the existing total smoking ban. Obtained data, including the results of logistic regression, showed that the situation of non-government, self-employed and government employees workers did not differ. This displayed the weakness of existing smoke-free legislation and its enforcement.

The strongest association with exposure to SHS at worksites was found for education attainment. This result correspond to previous reports revealing that a low level of education of workers is related to higher odds for SHS exposure in the workplace $[12,13,14,15,16]$. A study by Twose et al. showed that participants from lower social classes, in which the prevalence of active smoking is higher, work in settings where smoking is frequent. Thus, they might have a high risk of working near smokers and be exposed to SHS [12]. This evidently may lead to disparities in the risk of exposure to SHS across socio-economic groups, and exacerbating the existing inequalities in health. In addition, most often these jobs are less prestigious and it may happen that employers pay less attention to implementing smoking restrictions, or employees are not in favour with such rules. The role of support for rules that prohibit smoking should be also underlined, especially because an association was noted between higher odds for SHS at worksite among workers declaring a low level of support for tobacco control policies. Twose et al. similarly indicated that educational level was inversely associated with exposure to ETS among females, and directly associated with exposure among malesn [12]. Moreover, results from the European Community Respiratory Health Survey II show that subjects who stopped full-time education before the age of 16 years were more likely to be exposed to SHS at work and at home [14]. In other studies, the authors also found that passive smoking is increasingly becoming a socio-economic issue, with a higher risk of becoming exposed to passive smoking in more deprived groups $[14,16,17]$. This follows change in the social gradient in cigarette smoking, with smoking becoming less common among persons with higher socio-economic status, and relatively more frequent in less affluent social groups [14]. Furthermore, Steil et al. showed that various demographic variables, including education or income, predict knowledge of health risks caused by SHS, attitudes, and preventive behaviours [18]. Kurtz et al. in a study on knowledge, attitudes and preventive efforts with regard to exposure to ETS in a sample of economically disadvantaged women residing in Michigan, USA, correspondingly found that deprived women were less knowledgeable about the adverse health effects of exposure to ETS, also had worse attitudes concerning exposure to ETS, and were less likely to take preventive steps to limit their exposure to ETS than were women who had better socio-economic background [19]. This underlined the need to expand knowledge of the dangers of smoking and SHS among the disadvantaged groups of the population. 
Table 1. Characteristics of male respondents, including non-smokers, exposed and non-exposed to environmental tobacco smoke at work site Characteristics

\begin{tabular}{|c|c|c|c|c|}
\hline \multirow[t]{3}{*}{ Characteristics } & \multicolumn{2}{|c|}{ Male exposed to SHS at worksite } & \multicolumn{2}{|c|}{ Male non-exposed to SHS at worksite } \\
\hline & $\begin{array}{c}\text { Total } \\
\mathrm{n}=280\end{array}$ & $\begin{array}{c}\text { Non-smokers } \\
\mathrm{n}=135\end{array}$ & $\begin{array}{c}\text { Total } \\
\mathrm{n}=477\end{array}$ & $\begin{array}{c}\text { Non-smokers } \\
\mathrm{n}=298\end{array}$ \\
\hline & $\mathrm{N}(\%)$ & $\mathrm{N}(\%)$ & $\mathrm{N}(\%)$ & $\mathrm{N}(\%)$ \\
\hline \multicolumn{5}{|l|}{ Age (years) } \\
\hline $15-29$ & $62(22.1)$ & $26(19.3)$ & $84(17.6)$ & $52(17.5)$ \\
\hline $30-39$ & $76(27.2)$ & $36(26.7)$ & $136(28.5)$ & $82(27.5)$ \\
\hline $40-49$ & $82(29.3)$ & $42(31.0)$ & $152(31.9)$ & $88(29.5)$ \\
\hline$\geq 50$ & $60(21.4)$ & $31(23.0)$ & $105(22.0)$ & $76(25.5)$ \\
\hline Missing & $0(0.0)$ & $0(0.0)$ & $0(0.0)$ & $0(0.0)$ \\
\hline \multicolumn{5}{|l|}{ Place of residence } \\
\hline Rural & $85(30.4)$ & $41(30.4)$ & $133(27.9)$ & $85(28.5)$ \\
\hline Urban & $195(69.6)$ & 94 (69.6) & $344(72.1)$ & $213(71.5)$ \\
\hline Missing & $0(0.0)$ & $0(0.0)$ & $0(0.0)$ & $0(0.0)$ \\
\hline \multicolumn{5}{|l|}{ Education } \\
\hline Primary & $86(30.9)$ & $44(33.1)^{\mathrm{a}}$ & $122(25.6)$ & $69(23.2)$ \\
\hline Secondary & $133(47.8)$ & $62(46.6)$ & $227(47.7)$ & $140(47.2)$ \\
\hline High & $59(21.2)$ & $27(20.3)^{\mathrm{a}}$ & $127(26.7)$ & $88(29.6)$ \\
\hline Missing & $2(0.7)$ & $1(1.5)$ & $1(0.2)$ & $1(0.3)$ \\
\hline \multicolumn{5}{|l|}{ Job classification } \\
\hline Government employee & $50(18.4)$ & $21(16.2)^{\mathrm{a}}$ & $110(23.7)$ & $73(25.1)$ \\
\hline Non-Government employee and self-employed & $222(81.6)$ & $109(83.8)^{\mathrm{a}}$ & $355(76.3)$ & $218(74.9)$ \\
\hline Missing & $8(2.9)$ & $5(3.7)$ & $12(2.5)$ & $7(2.3)$ \\
\hline \multicolumn{5}{|l|}{ Asset index } \\
\hline Low & $9(3.2)$ & $3(2.2)$ & $20(4.3)$ & $12(4.1)$ \\
\hline Mid & $55(19.9)$ & $22(16.4)$ & $102(21.9)$ & $55(19.0)$ \\
\hline High & $213(76.9)$ & $109(81.3)$ & $344(73.8)$ & $223(76.9)$ \\
\hline Missing & $3(1.1)$ & $1(0.7)$ & $11(2.3)$ & $8(2.7)$ \\
\hline \multicolumn{5}{|l|}{ Awareness of SHS health consequences } \\
\hline Yes & $262(94.9)$ & $128(95.5)$ & $448(94.3)$ & $284(95.6)$ \\
\hline No & $14(5.1)$ & $6(4.5)$ & $27(5.7)$ & $13(4.4)$ \\
\hline Missing & $4(1.4)$ & $1(0.7)$ & $2(0.4)$ & $1(0.3)$ \\
\hline \multicolumn{5}{|l|}{ Awareness of smoking health consequences } \\
\hline Yes & $266(95.7)$ & $132(97.8)$ & $464(97.3)$ & $292(98.0)$ \\
\hline No & $12(4.3)$ & $3(2.2)$ & $13(2.7)$ & $6(2.0)$ \\
\hline Missing & $2(0.7)$ & $0(0.0)$ & $0(0.0)$ & $0(0.0)$ \\
\hline \multicolumn{5}{|l|}{ Support for tobacco control policies } \\
\hline High & $103(37.0)$ & $65(48.5)^{\mathrm{a}}$ & $218(46.1)$ & $176(59.7)$ \\
\hline Medium & $63(22.7)$ & $37(27.6)$ & $111(23.5)$ & $72(24.4)$ \\
\hline Low & $112(40.3)$ & $32(23.9)^{\mathrm{a}}$ & 144 (30.4) & $47(15.9)$ \\
\hline Missing & $2(0.7)$ & $1(0.7)$ & $4(0.8)$ & $3(1.0)$ \\
\hline \multicolumn{5}{|l|}{ Work smoking policy in indoor areas } \\
\hline Smoking allowed everywhere & $61(21.8)$ & $22(16.3)^{c}$ & $3(0.6)$ & $0(0.0)$ \\
\hline Smoking allowed in some indoor areas & $129(46.1)$ & $66(48.9)^{c}$ & $66(13.9)$ & $43(14.5)$ \\
\hline Smoking prohibited in all indoor areas & $56(20.0)$ & $28(20.7)^{c}$ & $385(81.1)$ & $239(80.7)$ \\
\hline No Policy & $34(12.1)$ & $19(14.1)^{c}$ & $21(4.4)$ & $14(4.7)$ \\
\hline Missing & $0(0.0)$ & $0(0.0)$ & $2(0.4)$ & $2(0.7)$ \\
\hline
\end{tabular}
Male non-exposed to SHS at worksite

a Non-smokers exposed vs. non-smokers non-exposed $\mathrm{p} \leq 0.05$

${ }^{b}$ Non-smokers exposed vs. non-smokers non-exposed $\mathrm{p} \leq 0.01$

'Non-smokers exposed vs. non-smokers non-exposed $\mathrm{p} \leq 0.001$

SHS - second hand tobacco smoke

Source: Global Adult Tobacco Survey Romania 2011. 
Table 2. Characteristics of female respondents including non-smokers exposed and non-exposed to second hand tobacco smoke at work site Global Adult Tobacco Survey Romania 2011

Characteristics

\begin{tabular}{cc} 
Female exposed to SHS at worksite \\
\hline $\begin{array}{c}\text { Total } \\
\mathrm{n}=164\end{array}$ & $\begin{array}{c}\text { Non-smokers } \\
\mathrm{n}=102\end{array}$ \\
\hline $\mathrm{N}(\%)$ & $\mathrm{N}(\%)$
\end{tabular}

Age (years)

$15-29$

30-39

40-49

$\geq 50$

Missing

Place of residence

\begin{tabular}{l} 
Rural \\
Urban \\
Missing \\
\hline Pducation
\end{tabular}

Primar

Primary

Secondary

High

Missing

Job classification

Government employed

Non-government employee and self-employed

Missing

Asset index

Low

Mid

High

Missing

Awareness on SHS health consequences

\begin{tabular}{|c|c|c|c|c|}
\hline Yes & $158(96.3)$ & $99(97.1)$ & $398(97.3)$ & 314 (97.5) \\
\hline No & $6(3.7)$ & $3(2.9)$ & $11(2.7)$ & $8(2.5)$ \\
\hline Missing & $0(0.0)$ & $0(0.0)$ & $3(0.7)$ & $2(0.6)$ \\
\hline \multicolumn{5}{|l|}{ Awareness on smoking health consequences } \\
\hline Yes & $162(98.8)$ & $102(100.0)$ & $402(97.6)$ & $318(98.2)$ \\
\hline No & $2(1.2)$ & $0(0.0)$ & $10(2.4)$ & $6(1.2)$ \\
\hline Missing & $0(0.0)$ & $0(0.0)$ & $0(0.0)$ & $0(0.0)$ \\
\hline \multicolumn{5}{|l|}{ Support for tobacco control policies } \\
\hline High & $75(46.3)$ & $58(57.4)$ & $235(57.6)$ & $206(64.4)$ \\
\hline Medium & $39(24.1)$ & $24(23.8)$ & $90(22.1)$ & $72(22.5)$ \\
\hline Low & $48(29.6)$ & 19 (18.8) & $83(20.3)$ & $42(13.1)$ \\
\hline Missing & $2(1.2)$ & $1(1.0)$ & $4(1.0)$ & $4(1.2)$ \\
\hline Smoking is allowed everywhere & $22(13.4)$ & $10(10.6)^{c}$ & $1(0.2)$ & $1(0.3)$ \\
\hline Smoking is allowed in some indoor areas & $96(58.5)$ & $63(67.0)^{c}$ & $59(14.4)$ & $44(13.6)$ \\
\hline Smoking is prohibited in all indoor areas & $33(20.1)$ & $21(22.4)^{c}$ & $347(84.4)$ & $275(85.1)$ \\
\hline No policy & $13(7.9)$ & $8(7.8)^{c}$ & $4(1.0)$ & $3(0.9)$ \\
\hline Missing & $0(0.0)$ & $0(0.0)$ & $1(0.2)$ & $1(0.3)$ \\
\hline
\end{tabular}

${ }^{a}$ Non-smokers exposed vs. non-smokers non-exposed $p \leq 0.05$.

b Non-smokers exposed vs. non-smokers non-exposed $\mathrm{p} \leq 0.01$.

'Non-smokers exposed vs. non-smokers non-exposed $\mathrm{p} \leq 0.001$.

'Non-smokers exposed vs. non-sm
SHS - second hand tobacco smoke

Female non-exposed to SHS at worksite

Total Non-smokers

$\mathrm{n}=412 \quad \mathrm{n}=324$

$\mathrm{N}(\%) \quad \mathrm{N}(\%)$

$\begin{array}{cccc}27(16.5) & 12(11.8) & 70(17.0) & 53(16.4) \\ 52(31.7) & 33(32.4) & 118(28.6) & 100(30.9) \\ 52(31.7) & 36(35.2) & 119(28.9) & 88(27.1) \\ 33(20.1) & 21(20.6) & 105(25.5) & 83(25.6) \\ 0(0.0) & 0(0.0) & 0(0.0) & 0(0.0)\end{array}$

\begin{tabular}{clll}
$38(23.2)$ & $22(21.6)$ & $118(28.6)$ & $93(28.7)$ \\
$126(76.8)$ & $80(78.4)$ & $294(71.4)$ & $231(71.3)$ \\
\hline
\end{tabular}

$\begin{array}{llll}0(0.0) & 0(0.0) & 0(0.0) & 0(0.0)\end{array}$

$\begin{array}{llcl}24(14.8) & 17(16.7) & 62(15.1) & 40(12.4) \\ 87(53.7) & 53(52.0) & 221(53.8) & 177(54.8) \\ 51(31.5) & 32(31.3) & 128(31.1) & 106(32.8)\end{array}$

$\begin{array}{llll}2(1.2) & 0(0.0) & 1(0.2) & 1(0.3)\end{array}$

$(32.5)$

$106(67.5)$

$34(34.0)$

$119(30.2)$

96 (30.9)

$7(4.3)$

$66(66.0)$

275 (69.8)

$215(69.1)$

$18(4.4)$

$13(4.0)$

5 (3.1)

27 (16.8)

$129(80.1) \quad 85(83.4)$

$3(2.9)$

$3(0.7)$

$2(0.6)$

14 (13.7)

55 (13.5)

$36(11.3)$

$349(87.8)$

282 (88.1)

$3(1.8)$

$0(0.0)$

$5(1.2)$

$4(1.2)$

$158(96.3)$

$97.1)$

398

$(0.3)$

1


Table 3. Odds Ratios (OR) and 95\% Confidence Intervals (Cl) for second hand tobacco smoke exposure at worksite to selected factors in nonsmoking employees - Global Adult Tobacco Survey Romania (2011)

\begin{tabular}{|c|c|c|c|c|c|}
\hline \multirow[t]{2}{*}{ Characteristics } & \multirow[b]{2}{*}{$\mathrm{N} \%$} & \multicolumn{2}{|c|}{$\begin{array}{l}\text { Univariable logistic } \\
\text { regression }\end{array}$} & \multicolumn{2}{|c|}{$\begin{array}{l}\text { Multivariable logistic } \\
\text { regression }^{\mathrm{a}}\end{array}$} \\
\hline & & OR & $95 \% \mathrm{Cl}$ & OR & $95 \% \mathrm{Cl}$ \\
\hline \multicolumn{6}{|l|}{ Gender } \\
\hline Men & 135 (31.2) & $1.44^{*}$ & $1.06-1.95$ & 1.29 & $0.94-1.76$ \\
\hline Women & 102 (23.9) & 1.00 & reference & 1.00 & reference \\
\hline Age (years) & & 1.00 & $0.98-1.01$ & & \\
\hline $15-29$ & $38(29.0)$ & 1.11 & $0.68-1.80$ & & \\
\hline $30-39$ & $69(27.5)$ & 1.16 & $0.76-1.76$ & & \\
\hline $40-49$ & $78(34.8)$ & 1.36 & $0.90-2.05$ & & \\
\hline$\geq 50$ & $52(24.6)$ & 1.00 & reference & & \\
\hline \multicolumn{6}{|l|}{ Place of residence } \\
\hline Rural & $63(26.1)$ & 1.00 & reference & & \\
\hline Urban & $174(28.2)$ & 1.11 & $0.79-1.55$ & & \\
\hline \multicolumn{6}{|l|}{ Education } \\
\hline Primary & $61(35.9)$ & $1.84 * *$ & $1.20-2.82$ & $1.88^{* *}$ & $1.21-2.92$ \\
\hline Secondary & $115(26.6)$ & 1.14 & $0.89-1.71$ & 1.20 & $0.83-1.74$ \\
\hline High & $59(23.3)$ & 1.00 & reference & 1.00 & reference \\
\hline \multicolumn{6}{|l|}{ Job classification } \\
\hline $\begin{array}{l}\text { Government } \\
\text { employed }\end{array}$ & 55 (24.6) & 1.00 & reference & & \\
\hline $\begin{array}{l}\text { Non-Government } \\
\text { employee and self- } \\
\text { employed }\end{array}$ & $175(28.8)$ & 1.24 & $0.87-1.77$ & & \\
\hline Asset index & & 1.00 & $0.91-1.10$ & & \\
\hline Low & $6(30.0)$ & 1.12 & $0.42-2.95$ & & \\
\hline Middle & $36(28.3)$ & 1.03 & $0.67-1.59$ & & \\
\hline High & $194(27.8)$ & 1.00 & reference & & \\
\hline \multicolumn{6}{|l|}{$\begin{array}{l}\text { Awareness on SHS } \\
\text { health consequences }\end{array}$} \\
\hline Yes & 227 (27.5) & 1.00 & reference & & \\
\hline No & $9(30.0)$ & 1.13 & $0.51-2.50$ & & \\
\hline
\end{tabular}

Awareness on

smoking health

consequences

\begin{tabular}{lccc}
\hline Yes & $234(27.7)$ & 1.00 & reference \\
\hline No & $3(20.0)$ & 0.65 & $0.18-2.33$ \\
\hline
\end{tabular}

Support for tobacco

control policies

\begin{tabular}{lccccc}
\hline High & $123(24.4)$ & 1.00 & reference & 1.00 & reference \\
\hline Medium & $61(29.8)$ & 1.32 & $0.92-1.89$ & 1.36 & $0.94-1.96$ \\
\hline Low & $51(36.4)$ & $1.78^{* *}$ & $1.19-2.66$ & $1.85^{* *}$ & $1.23-2.79$ \\
\hline
\end{tabular}

a Fully adjusted model including all statistically significant characteristics.

* $p \leq 0.05$

$* * 0 \leq 0.0$

*** $\mathrm{p} \leq 0.001$

Study limitations and strengths. Self-report methods are the most convenient and cheapest way to collect data on SHS or active smoking from a large number of people in a short time. However, there are some limitations, the main one being that in obtaining answers about SHS or smoking there may be recall bias. This may cause underestimation of SHS exposure. Moreover, the health effects of exposure to environmental tobacco smoke depend on several factors, including the number of smokers in the room, the number of cigarettes smoked by those individuals, and the duration of exposure. Unfortunately, the GATS questionnaire does not allow careful measurement of these parameters.

The best method for assessing the level of exposure to SHS is to measure markers or biomarkers, including carbon monoxide in exhaled air and the level of cotinine in saliva, blood, urine or hair $[20,21]$. The data presented in the current study have not been verified by any biomarkers. This method is also not commonly used for large population surveys, due to high costs and time-consuming procedures [22, 23]. Moreover collecting saliva, urine or blood from respondents for analysis might increase the number of refusals and lead to non-participation bias. Given this, questionnaires seem to be valid tools in most epidemiological studies [24]. GATS is a nation-representative survey of adults 15 years of age or older using a standard core survey, sample design, and data collection and management procedures. To-date, GATS has probably provided most valid statistics on worksites SHS exposure and smoking in Romania [6].

\section{CONCLUSIONS}

There are bans in indoor workplaces and offices in most EU countries, but in spite of these legal restrictions, compliance has often been lax [25]. GATS provided evidence that many non-smoking workers in Romania are involuntarily exposed to ETS during their working day. GATS also documented predictors of SHS exposure at worksites. It seems that secondhand smoke exposure in workplaces need to be reduced, especially among non-government, self-employed and poorly educated workers. These findings have important implications for informing tobacco control efforts focused on decreasing SHS exposure, and changing social norms regarding smoking in the workplace in Romania. Smoke-free legislation and tobacco control measures implemented in Romania need to be strengthened and their comprehensiveness improved.

\section{Acknowledgements}

Financial support was provided by the Bloomberg Initiative to Reduce Tobacco Use, a programme of Bloomberg Philanthropies. The authors thank the Survey Team involved in GATS Romania and the Romanian GATS Partners: Ministry of Health, National Institute of Public Health, National Statistic Training Centre TOTEM Communication, and representatives of the World Health Organization, Centres for Disease Control and Prevention, CDC Foundation, Johns Hopkins Bloomberg, School of Public Health, and RTI International for their contributions. CDC, Atlanta, USA, made available the GATS data in the public domain. A Full list of contributors to the study is available at: http://www.who. int/tobacco/surveillance/survey/gats/romania/en/index.html

\section{REFERENCES}

1. World Health Organization. Global estimate of the burden of disease from second-hand smoke. World Health Organization, Geneva, 2010.

2. World Health Organization. Second hand smoke, assessing the environmental burden of disease at national and local levels. World Health Organization, Geneva, 2010.

3. U.S. Department of Health and Human Services. The Health Consequences of Involuntary Exposure to Tobacco Smoke: A Report of the Surgeon General. Centers for Disease Control and Prevention, Coordinating Center for Health Promotion, National Center for Chronic Disease Prevention and Health Promotion, Office on Smoking 
and Health, U.S. Department of Health and Human Services, Atlanta, GA 2006.

4. Jaakkola Maritta S, Ritva Piipari, Niina Jaakkola, Jouni J. K. Jaakkola. Environmental tobacco smoke and adult-onset asthma: a populationbased incident case-control study. Am J Pub Health. 2003; 93: 20552060.

5. World Health Organization. WHO global report: mortality attributable to tobacco. World Health Organization, Geneva, Switzerland, 2012.

6. Global Adult Tobacco Survey (GATS). Romania Country Report. Ministry of Health Romania. Eikon, Bucarest, 2012. http://www.who. int/tobacco/sur.... html (Accessed July 2014).

7. Kaleta D, Usidame B, Dziankowska-Zaborszczyk E, MakowiecDąbrowska T. Correlates of cessation success among Romanian adults. BioMed Res Int. 2014, Article ID 675496, 11 pages, http:// dx.doi.org/10.1155/2014.

8. Kaleta D, Makowiec-Dąbrowska T, Dziankowska-Zaborszczyk E, Fronczak A. Prevalence and socio-demographic correlates of daily cigarette smoking in Poland: results from the Global Adult Tobacco Survey (2009-2010). Int J Occup Med Environ Health. 2012 Jun; 25(2): 126-36. doi: 10.2478/S13382-012-0016-8.

9. Centers for Disease Control and Prevention (CDC), Global Tobacco Surveillance System. Global adult tobacco survey. Centers for Disease Control and Prevention, Atlanta,1999.

10. King BA, Mirza SA, Babb SD. GATS Collaborating Group. A crosscountry comparison of secondhand smoke exposure among adults: findings from the Global Adult Tobacco Survey (GATS). Tob Control 2012; 22(4): e5, 2013. doi: 10.1136/tobaccocontrol-2012-050582.

11. Special Eurobarometer 385/ Wave EB 77.1 - TNS Opinion \& Social. Attitudes of Europeans towards tobacco. June 2012. http://ec.europa. eu/public_opi.... (Accessed at: June 2014).

12. Twose J, Schiaffino A, García M, Borras JM, Fernández E. Correlates of exposure to second-hand smoke in an urban Mediterranean population. BMC Pub Health 2007; 7: 194.

13. Nebot M, Lopez M., Tomas Z, Ariza C, Borrell C, Villalbi J. Exposure to environmental tobacco smoke at work and at home: a population based survey. Tob Control. 2004; 13(1): 95. doi: 10.1136/tc.2003.006221.

14. Janson C, Künzli N, de Marco R, Chinn S, Jarvis D, Svanes C, Heinrich J, Jõgi R, Gislason T, Sunyer J, Ackermann-Liebrich U., Antó JM,
Cerveri I, Kerhof M, Leynaert B, Luczynska C, Neukirch F, Vermeire $\mathrm{P}, \mathrm{Wjst} \mathrm{M}$, Burney P. Changes in active and passive smoking in the European Community Respiratory Health Survey. Eur Respir J. 2006; 27(3): 517-24.

15. Whitlock G, MacMahon S, Vander Hoorn S, Davis P, Jackson R, Norton R. Association of environmental tobacco smoke exposure with socioeconomic status in a population of 7725 New Zealanders. Tob Control. 1998; 7: 276-80.

16. Faggiano F, Versino E, Lemma P. Decennial trends of social differentials in smoking habits in Italy. Cancer Causes Control. 2001; 12: 665-671.

17. Jefferis BJ, Power C, Graham H, Manor O. Changing social gradients in cigarette smoking and cessation over two decades of adult follow-up in a British birth cohort. J Public Health (Oxf) 2004; 26: 13-18.

18. Steil AK, Lorenzo L, Sydeman S. Demographic variables are associated with knowledge, attitudes, and preventive behaviors related to environmental tobacco smoke. Nicotine Tob Res. 2010; 12(6): 674-678. doi: 10.1093/ntr/ntq065.

19. Kurtz M, Kurtz J, Contreras D, Booth C. Knowledge and attitudes of economically disadvantaged women regarding exposure to environmental tobacco smoke. Eur J Public Health 2003; 13: 171-176.

20. Jaakkola MS, Jaakkola JJ. Assessment of exposure to environmental tobacco smoke. Eur Respir J. 1997; 10: 2384-2397.

21. Max W, Sung HY, Shi Y. Who is exposed to secondhand smoke? Selfreported and serum cotinine measured exposure in the U.S., 1999-2006. Int J Environ Res Public Health 2009; 6: 1633-48.

22. James H, Tizabi Y, Taylor R. Rapid method for the simultaneous measurement of nicotine and cotinine in urine and serum by gas chromatography-mass spectrometry. J Chromatogr B Biomed Sci Appl. 1998; 708(1-2): 87-93.

23. Jarvis M, Tunstall-Pedoe H, Feyerabend C, Vesey C, Salloojee Y. Biochemical markers of smoke absorption and self- reported exposure to passive smoking. J Epidemiol Community Health. 1984; 38(4):335-9.

24. Patrick D L, Cheadle A, Thompson DC, Diehr P, Koepsell T, Kinne S. The Validity of Self-Reported Smoking: A Review and Meta-Analysis. Am J Public Health. 1994; 84: 1086-1093.

25. Muilenburg JL, Legge JS Jr, Burdell A. Indoor smoking bans in Bulgaria, Croatia, Northern Cyprus, Romania and Turkey. Tobacco Control 2010;19:417e420. doi:10.1136/tc.2009.029769 